\title{
ESCOLHA DA CARREIRA E PROCESSO DE CONSTRUCุÃO DA IDENTIDADE PROFISSIONAL DOCENTE ${ }^{22}$
}

\author{
Adriane de Castro Menezes Sales* \\ Edna Maria Querido de Oliveira Chamon**
}

RESUMO: O trabalho teve como objetivo analisar os fatores intervenientes na escolha da profissão, assim como a influência desses elementos na construção da identidade profissional docente. $\mathrm{O}$ método foi descritivo, com abordagem quantitativa, baseado em um questionário fechado. A amostra foi de 964 sujeitos e a análise de dados dos questionários foi feita com auxílio do software Sphinx®. Nos resultados, observou-se forte influência de ideários sociais nas concepções elaboradas pelos sujeitos sobre a profissão docente e nos fatores declarados para a escolha profissional (concepções de educação ligadas a redenção social; visão idealizada do exercício da docência). Destacam-se, também, os conflitos e a complexidade vivenciada pelos graduandos diante da necessidade de sentirem-se prontos a responder às demandas e exigências da escola, do contexto social e do mercado de trabalho.

Palavras-chave: Escolha Profissional. Identidade Profissional. Professores.

\section{CAREER CHOICE AND CONSTRUCTION OF TEACHERS' PROFESSIONAL IDENTITIES}

ABSTRACT: The objective of the study was to analyse the factors bearing down most strongly upon somebody choosing the teaching profession, as well as the influence of these elements in the formation of a teacher's professional identity. A descriptive method was used with a quantitative approach based on a closed-ended questionnaire. The sample was composed of 964 subjects and the questionnaire data analysis was performed by the Sphinx ${ }^{\circledR}$ software. The results showed a strong influence of social ideals in the concepts elaborated by the subjects when describing the teaching profession and these social ideals also influenced their choice of the profession (concepts of education linked to social redemption; an idealized vision of the practice of teaching). Also, it points out the conflicts and complexity experienced by the students, given the need to feel ready to meet the demands and requirements of the school, in the social context, and in the context of the labour market.

Keywords: Professional Choice. Professional Identity. Teachers.

\footnotetext{
* Mestre em Gestão e Desenvolvimento Regional pela Universidade de Taubaté (UNITAU/SP). E-mail: ammsalles@gmail.com

** Doutora em Psicologia Social pela Université de Toulouse II - Le Mirail Toulouse, França; Pós-Doutora em Educação pela Universidade de Campinas (UNICAMP). E-mail: edna.chamon@gmail.com
} 


\section{Introdução}

As pressões exercidas junto aos profissionais da educação têm gerado muitas inquietações, principalmente sobre as responsabilidades atribuídas ao educador, questões salariais e condições de trabalho. Nessa linha, Cunha (2006) aborda três questões importantes. A primeira referese à desvalorização dos docentes, questão sociopolítica que incide diretamente sobre sua atuação, sua motivação e, consequentemente, seu processo de formação. Segundo a autora "No plano político e social há, [...], uma evidente desvalorização do professor. Ele não mais é reconhecido como capaz de honrar a confiança da sociedade para educação de seus jovens e crianças" (CUNHA, 2006, p. 266).

A segunda é a fragilidade com que se encontram os professores diante do perfil concorrencial do processo educativo. Ocorre, atualmente, uma distorção no sistema. O professor vê-se obrigado a ofertar seus serviços (o ensino) como se fosse um produto ou bem material, ora negociado para atender às solicitações do mercado e à necessidade de aquisição de uma certificação de qualidade. E, por último, mas igualmente complexa, a questão do desempenho docente e discente que, tratada de forma correlata, alija uma série de fatores que são extraescolares e curriculares, com o agravante de atribuir aos professores todas as responsabilidades sobre os resultados da educação brasileira.

Nesse contexto, é importante observar que, em relação ao prestígio, a educação como processo e os educadores têm imagem positiva. Para Nóvoa (1995), esse paradoxo pode ser compreendido se considerado que estão em jogo as visões idealizadas e a realidade concreta das situações de ensino e, ainda, o reconhecimento de que a educação é um fator primordial ao desenvolvimento.

No entanto, devido à proporção da questão e à proposta do presente artigo, faz-se necessário direcionar, para o professor, a abordagem da crise e, mais, mergulhar diretamente na dimensão de sua identidade profissional docente. 


\section{Referencial teórico}

A sociedade contemporânea - fortemente marcada pela influência da tecnologia, da multimídia, do conhecimento e da globalização - dá uma finalidade diferenciada e impõe um grande desafio à ação educativa escolar: dar condições aos alunos de desenvolverem habilidades para lidar com os desafios da sociedade atual, além de torná-los aptos a compreender criticamente os conhecimentos, com propriedade suficiente para transformá-los - reconstruí-los (PIMENTA, 2005).

Essas questões, no entanto, não dependem exclusivamente da educação, da escola e/ou do professor; são componentes do processo educacional e fazem parte da teia de complexidades da sociedade contemporânea e de seus comprometimentos com o capitalismo (CHAMON, 2003).

Diante desse contexto, é necessária, numa primeira instância, a reflexão sobre a crise social vivida neste início de século - crise de paradigmas e de expectativas não alcançadas pela modernidade - e a maneira como essa crise se manifesta na construção identitária específica dos professores.

\section{Docência e crise identitária}

Segundo Chamon (2003), percebe-se que a insegurança em relação ao futuro e aos referenciais a serem utilizados para a "sobrevivência" não são prerrogativa única dos professores; toda a sociedade tem buscado situar-se nesse processo, ou seja, encontra-se instalada uma crise de identidade que abrange todo o meio social. Esse é o chamado sentido amplo da crise identitária. Um segundo sentido, restrito, que representa uma espécie de reflexo do primeiro, adquire especificidade própria quando referido à docência.

Dois aspectos podem ser considerados responsáveis por essa crise de identidade em sentido amplo. Tem-se, primeiramente, a constatação, cada vez mais clara, da incapacidade de se cumprirem as promessas da modernidade. A certeza proporcionada pela da ciência, o bem-estar gerado pela economia, a emancipação política garantida pelo Estado parecem cada vez mais distantes. O segundo aspecto refere-se aos fenômenos 
culturais e identitários associados à aceleração do processo de globalização. De fato, o conjunto dos elementos globalizados - bens de consumo ou de comunicação, tecnologia ou instrumentos, fluxos de capital ou de informação - não é próprio de nenhuma cultura, ou seja, a globalização promove uma dessocialização dos indivíduos, restringindo sua comunicação ao uso dos objetos e signos globalizados comuns: surge a ruptura entre o mundo instrumental (globalizado) e o mundo simbólico (identidade cultural) dos indivíduos (CHAMON, 2003).

Ao mesmo tempo que cria essa "cultura" de significados préfabricados, a globalização incita reações de fechamento. Gohn (1999) vê as comunidades se isolando, buscando proteção contra a invasão cultural representada pela globalização.

Já em sentido mais restrito, para o professor, a crise é de sua identidade profissional, o que tem consequências biográficas profundas em função da centralidade do trabalho no mundo moderno.

Essa crise desenha-se a partir do pós-Guerra, quando as elites passaram cada vez menos a ser recrutadas com base em critérios escolares, diminuindo o prestígio dos professores (NÓVOA, 2000). Em seguida, nos anos 1960, os professores eram identificados por meio de estatísticas e papéis sociais a eles atribuídos. Nos anos 1970, esses professores foram transformados em culpados pelo fracasso escolar e principais agentes reprodutores das desigualdades sociais (BUENO, 2000). A partir dos anos 1980, multiplicaram-se as instâncias de controle no sistema educacional e implantaram-se sistemas de avaliação institucional. Buscava-se uma racionalização do ensino representada por um modelo que "procura separar o trabalho de concepção das tarefas de realização; ou, dito de outro modo, procura separar a elaboração dos currículos e dos programas de sua concretização pedagógica" (NÓVOA, 1998, p. 26-27).

Dentro dessa perspectiva mais específica da realidade e das problemáticas que mantêm relações diretas com os docentes, compreendemse os processos de crise profissional como parte de uma

crise identitária geral, cujo aspecto principal aqui é a incapacidade do sistema educacional de superar injustiças e desigualdades sociais (uma das promessas da modernidade), se projeta na crise identitária específica (crise da identidade profissional) do professor. A manifestação dessa crise em sentido restrito pode ser vista a partir de uma: a) progressiva incompreensão e ausência de reconhecimento social da profissão docente; [...] b) indefinição institucional da escola a 
nível organizativo e pedagógico, a par da proliferação de papéis exigidos ao professor; [...] c) deficiente percepção por parte dos professores do que é sua profissão. Temos, então, os professores imersos em uma incompreensão / indefinição /incerteza quanto ao que eles são e fazem enquanto profissionais, por parte da sociedade, da escola e de si mesmos (CHAMON, 2003, p. 22).

\section{Identidade e identidade profissional docente}

A concepção de identidade adotada aqui se aproxima do conceito de self, tal como o concebe George Mead, isto é, fruto da interação social, que aparece como introjeção da maneira como os outros percebem o sujeito (L'ECUYER apud CHAMON, 2003).

Mais especificamente, encontramos em Mead a ideia de que o self é constituído por uma componente sociológica ( $\mathrm{mim}$ - em inglês me), que seria a interiorização dos papéis sociais, e de uma componente mais pessoal (Eu - em inglês, I) (GRIGOROWITSCHS, 2008).

O self emerge de uma tensão dialética entre suas componentes pessoal e sociológica. $\mathrm{O}$ eu representa o aspecto criador do self, forma de resposta a atitudes do outro que foram interiorizadas; o mim corresponde ao conjunto organizado de julgamentos do outro que o self endossa.

As relações com o outro geram também identidades sociais, isto é, sentimentos de pertença a um grupo com o qual o indivíduo é susceptível de se identificar. Entre as muitas identidades sociais do indivíduo, a identidade profissional é aquela ancorada nas representações, práticas e saberes profissionais, que depende do contexto de exercício profissional do indivíduo. Como indica Pimenta (2005, p. 18-19), "uma identidade profissional se constrói, pois, a partir da significação social da profissão; da revisão das tradições. Mas também da reafirmação de práticas consagradas culturalmente e que permanecem significativas".

No caso do professor, a formação inicial é "rotineiramente considerada uma ponte ritual entre o mundo do aluno e o mundo do professor [devendo assinalar o] período em que a prática do ser professor é inicialmente informada pelas teorias educacionais e ocasião em que a metamorfose entre o papel de ser professor e de aluno começa a ocorrer" (MIZUKAMI; REALI, 2002, p. 124).

Borba (2001, p. 39) afirma que a atividade profissional docente traz “[...] significados advindos das pertenças ao modelo 'ser professor' 
construído na relação afetiva, durante a socialização primária e mediante outras representações políticas, religiosas, étnicas e culturais advindas do grupo familiar, da comunidade e da sua classe social".

Em se tratando de identidade profissional, far-se-á um recorte fundamentado em Nóvoa (1995, p. 115), que a aponta como

[...] uma construção que tem uma dimensão espacio-temporal, atravessa a vida profissional desde a fase da opção pela profissão até a reforma, passando pelo tempo concreto da formação inicial e pelos diferentes espaços institucionais onde a profissão de desenrola. (...) É uma construção que tem a marca das experiências feitas, das opções tomadas, das práticas desenvolvidas, das continuidades e descontinuidades, quer ao nível das representações quer ao nível do trabalho concreto.

Nessa perspectiva, é possível vislumbrar duas dimensões da identidade profissional: o Eu profissional e o Ideal profissional.

$\mathrm{O}$ Eu profissional pode ser caracterizado como a imagem que o indivíduo construiu de si mesmo na interação profissional, dentro de contextos profissionais. Ela pode ser considerada como o produto da imagem que os outros enviam ao sujeito - e que ele próprio integrou - e de um aspecto criativo, reação do indivíduo à situação profissional.

Quanto ao Ideal profissional, pode-se defini-lo como o modelo (visto como conjunto de valores e opções adotadas) do "bom profissional" que o indivíduo quer vir a ser.

Essas dimensões da identidade profissional são construídas (ao mesmo tempo que influenciam) nas motivações para a escolha da carreira e nas percepções sobre a profissão docente, que são estudadas neste trabalho.

\section{Materiais e métodos}

Esta pesquisa é o resultado de um estudo transversal, descritivo, com abordagem quantitativa. Envolveu 964 sujeitos de um universo de 2.215 alunos matriculados entre o primeiro e o quinto semestres de um curso de Pedagogia ofertado por uma instituição privada de ensino superior localizada em Belém, estado do Pará.

O instrumento utilizado foi um questionário com questões fechadas e o tratamento estatístico das respostas obtidas, realizado com o 
auxílio do software Sphinx ${ }^{\circledR}$, permitiu a análise descritiva dos dados. O questionário é uma adaptação/ampliação do instrumento utilizado por Chamon (2003) em pesquisas relativas à formação e à identidade. O questionário apresenta 99 questões divididas em cinco categorias de análise (eixos).

Neste artigo, são apresentadas apenas as questões referentes aos fatores intervenientes na escolha da profissão e na percepção dos sujeitos sobre a carreira docente, assim como sobre a influência desses elementos na construção da identidade profissional do professor, configurados como objetivo de análise deste trabalho.

Para a análise da identidade e da escolha da profissão, as questões apresentavam conjuntos de assertivas entre as quais as mais significativas deveriam ser selecionadas pelos sujeitos. Para a percepção sobre a carreira docente, uma escala de Likert em cinco níveis (discordo totalmente, discordo, nem concordo nem discordo, concordo e concordo totalmente) foi proposta para avaliação de um conjunto de afirmações.

\section{Caracterização da amostra}

Antes da análise dos dados propriamente ditos, apresentam-se, em linhas gerais, as características dos sujeitos desta pesquisa.

Quanto ao gênero, há predominância do sexo feminino $-\mathrm{Nf}=$ 909 (94,3\%), em relação ao grupo masculino, que é de apenas $\mathrm{Nm}=55$ (5,7\%). A idade média dos sujeitos situa-se pouco acima de 30 anos.

Em relação à renda pessoal, verifica-se que a maioria $\mathrm{N}=734$ $(76,2 \%)$ ganha até três salários mínimos, enquanto $\mathrm{N}=211(21,9 \%)$ tem renda pessoal que varia entre três e dez salários mínimos. Apenas $\mathrm{N}=16$ $(1,7 \%)$ ganham acima de dez salários.

Sobre a experiência prévia dos sujeitos no magistério, $61,7 \%$ da amostra não têm experiência; 9,5\% têm experiência de 1 e 4 anos; 11,3\%, de 5 a 8 anos; 7,2\%, entre 9 e 12 anos; e 9,5\% atuam por período maior do que 13 anos. Sete sujeitos não responderam.

A distribuição dos alunos foi organizada em três grupos: $\mathrm{N} 1=$ 310 alunos do $1^{\circ}$ e $2^{\circ}$ semestres; $\mathrm{N} 2=511$ alunos do $3^{\circ}$ e $4^{\circ}$ semestres; e, $\mathrm{N} 3=143$ alunos do $5^{\circ}$ semestre. $\mathrm{Na}$ instituição pesquisada não existiam alunos de $6^{\circ}$ semestre no momento da coleta de dados. 
No que se refere ao recurso utilizado para a formação, os resultados apontaram que 49,2\% financiam o curso com recursos próprios; $50,1 \%$ contam com o auxílio de familiares/outras pessoas; e, apenas $0,4 \%$ contam com incentivo das instituições onde trabalham. Cerca de $0,3 \%$ dos sujeitos não respondeu a esta questão.

\section{Resultados e discussões}

\section{Fatores motivadores para a escolha da profissão}

A Figura 1 indica os fatores que motivaram a escolha pela carreira do magistério. Nesse caso, o sujeito poderia escolher até duas entre as cinco opções colocadas. Os resultados obtidos junto à amostra total de sujeitos $(\mathrm{Nt}=964)$ demonstram que as opções ligadas à melhoria do ensino (58,8\% - 567 citações) e ao prazer de ensinar (44,8\% - 432 citações) são preponderantes em relação às demais escolhas. As alternativas ter contato com pessoas $(24 \%$ - 231 citações $)$, ter uma carreira em geral ( $21,2 \%$ - 204 citações) e o tipo de trabalho (10,4\% - 100 citações), juntas, não superam o percentual obtido na primeira alternativa.

\section{FIGURA 1}

FATORES MOTIVADORES PARA A ESCOLHA DA PROFISSÃO

Escol haduas razõesque possam definir a sua motivação paraser professor.

\begin{tabular}{|l|r||r|}
\hline \multicolumn{1}{|l||}{} & Qt & $\%$ obs. \\
\hline Melhoraro ensino & 567 & $58,8 \%$ \\
\hline \\
\hline Por prazer & 432 & $44,8 \%$ \\
\hline Ter contatocompesscas & 231 & $24,0 \%$ \\
\hline Para ter umac arreira & 204 & $21,2 \%$ \\
\hline Otipo de trabalho & 100 & $10,4 \%$ \\
\hline Total & 964 & \\
\hline
\end{tabular}




\section{FIGURA 2}

FATORES MOTIVADORES PARA A ESCOLHA DA PROFISSÃO - ALUNOS DO $1^{\circ}$ ANO

Esod hadues rezões que possamdefinir a sua nutivação paraser professor.

\begin{tabular}{|c|c|c|}
\hline & $\mathrm{Q}$ & \%obs \\
\hline Mathara ro ensino & 776 & $56,8 \%$ \\
\hline Por prazer & 142 & $45,8 \%$ \\
\hline Paraterumacareira & 74 & $23,9 \%$ \\
\hline Ter cortatocompesscas & $\boldsymbol{\theta}$ & $\mathbf{2 2 , 3 \%}$ \\
\hline Otipo de trabalho & 41 & $13,2 \%$ \\
\hline Total & 310 & \\
\hline
\end{tabular}

A Figura 2 refere-se às motivações do grupo 1 (alunos do $1^{\circ}$ ano). Observa-se que os principais fatores de motivação permanecem inalterados, ou seja, a melhoria do ensino em primeiro lugar, com 56,8\% (176 citações), seguida pelo prazer de ensinar, que obteve 45,8\%, 142 das citações feitas.

\section{FIGURA 3}

FATORES MOTIVADORES PARA A ESCOLHA DA PROFISSÃO - ALUNOS DO $2^{\circ}$ ANO

Escol haduas razões que possamdefinir a sua motivação paraser professor.

\begin{tabular}{|l|r||r|}
\hline \multicolumn{1}{|c||}{ Qt } & $\%$ obs. \\
\hline Melhoraro ensino & 302 & $59,1 \%$ \\
\hline Por prazer & 233 & $45,6 \%$ \\
\hline Ter contatocompesscas & 128 & $25,0 \%$ \\
\hline Para terumacarreira & 106 & $20,7 \%$ \\
\hline Otipo de traballho & 46 & $9,0 \%$ \\
\hline Total & 511 & \\
\hline
\end{tabular}


FIGURA 4

FATORES MOTIVADORES PARA A ESCOLHA DA PROFISSÃO - ALUNOS DO $3^{\circ}$ ANO

Escol haduas razõesque possamdefinir a sua motivação paraser professor.

\begin{tabular}{|c|c|c|}
\hline & Qt & \%obs. \\
\hline Melhor aro ensino & 89 & $62,2 \%$ \\
\hline Por prazer & 57 & $39,9 \%$ \\
\hline Ter contatocompessoas & 34 & $23,8 \%$ \\
\hline Para terumacarreira & 24 & $16,8 \%$ \\
\hline Otipo de trabalho & $\mathbf{1 3}$ & $9,1 \%$ \\
\hline Total & 143 & \\
\hline
\end{tabular}

Quanto aos dados dos grupos 2 e 3 , alunos do $2^{\circ}$ e $3^{\circ}$ anos, respectivamente, as Figuras 3 e 4 demonstram que os resultados obtidos replicam, proporcionalmente, a escala apresentada na Figura 1. O grupo 2 apresenta para a melhoria do ensino um percentual de $59,1 \%$ de escolha (302 citações); para o prazer de ensinar, 45,6\% (233 citações); ter contato com pessoas, 25\% (128 citações); ter uma carreira, 20,7\% (106 citações); e para o tipo de trabalho, 9\%, com 46 citações.

No grupo 3, a melhoria do ensino atingiu $62,2 \%$ das escolhas (89 citações); o prazer de ensinar, na segunda colocação, atingiu 39,9\%, com 57 citações; ter contato com pessoas obteve 23,8\% (34 citações); e ter uma carreira e o tipo de trabalho obtiveram 16,8\% (24 citações) e 9,1\% (13 citações), respectivamente.

Observa-se que o fator preponderante de motivação é a melhoria do ensino, que se destaca em todos os grupos (Figuras 2, 3 e 4). Isso sugere que os sujeitos se sentem responsáveis por essa melhoria ou, dito de outra forma, que a ação docente é fator significativo na melhoria do ensino.

Nesse sentido, Nóvoa (2003) comenta que, atualmente, os professores são vítimas de um discurso de excessos que, de forma mitológica, atribui à ação docente a salvação da humanidade e que, durante muito tempo, foi alimentado pela conivência deles.

Outra questão a ser considerada é o fato de que, em todos os grupos, a opção relacionada ao tipo de trabalho foi a última escolhida pelos sujeitos. Tal aspecto é instigante, dada a relação que o "tipo de trabalho" tem com a escolha da carreira de cada indivíduo. 
Cabe destacar, de acordo com Frozino (2006, p. 52), que "[...] é preciso observar os desejos, as necessidades e as motivações de cada um [...] as estruturas socioeconômicas, as características de mercado de trabalho, os valores dominantes [...] o contexto histórico dentro do qual os encaminhamentos profissionais se inscrevem". Nesse sentido, a discrepância entre os resultados obtidos aponta para uma contradição entre a motivação (melhoria do ensino) e a compreensão da realidade do mercado e do contexto socioprofissional escolhido (tipo de trabalho).

Esse resultado aponta para um reforço do Ideal Profissional, dimensão da identidade profissional, como já indicado, que caracteriza o "bom professor" na concepção do indivíduo. Aponta, também, para um estágio ainda incipiente do Eu profissional, resultante, muito possivelmente, da pouca experiência de magistério da maioria dos sujeitos $(61,7 \%$ não possuem experiência na área).

\section{b. Fatores determinantes para a escolha da profissão}

Sobre os fatores determinantes para a escolha do magistério, os resultados apresentados na Figura 5, referentes à amostra total de sujeitos $(\mathrm{N}=964)$, demonstram que o ingresso na área do magistério está ligado a diversas razões, sem preponderância para nenhuma específica. Nesse caso, o sujeito poderia escolher até três entre as doze opções colocadas.

FIGURA 5

FATORES DETERMINANTES PARA A ESCOLHA DA PROFISSÃO - AMOSTRA TOTAL

\begin{tabular}{|c|c|c|}
\hline & Qt. & $\%$ obs. \\
\hline Para aprenderconstantem ente & 202 & $21,0 \%$ \\
\hline Para fazer algo de útil à sociedade & 183 & $19,0 \%$ \\
\hline Por opção & 173 & $17,9 \%$ \\
\hline Para formaroutras pessoas & 172 & $17,8 \%$ \\
\hline Sempre son heicom is so & 151 & $15,7 \%$ \\
\hline Pelo prazer de explicar e se fazer entender & 144 & $14,9 \%$ \\
\hline Pelas oportunidades do mercado de trabalho & 136 & $14,1 \%$ \\
\hline Pa ra u tilizar m in has capacidades & 103 & $10,7 \%$ \\
\hline Para ter um futuro es tável & 40 & $4,1 \%$ \\
\hline Para ter a u to nomia & 38 & $3,9 \%$ \\
\hline Porfalta de opção & 24 & $2,5 \%$ \\
\hline Para ter responsabilid ade & 16 & $1,7 \%$ \\
\hline Tot al & 964 & \\
\hline
\end{tabular}


Nesse sentido, destacam-se os fatores: aprendizagem constante (21\% - 202 citações); utilidade (importância) para a sociedade $(19 \%-83$ citações); por opção (17,9\% - 173 citações); a formação de outras pessoas (17,8\% - 172 citações). Pode-se dizer que, num segundo bloco de escolhas, estão as questões ligadas aos sentimentos em relação à profissão (15,7\% - 151 citações); pelo prazer de explicar e se fazer entender (ensinar), com 14,9\% (144 citações); pelas oportunidades do mercado de trabalho (14,1\% - 136 citações); e a utilização (aproveitamento) das capacidades pessoais, com 10,7\% (103 citações). E, como um último agrupamento de fatores, selecionados com menores índices de escolha, encontram-se os seguintes itens: a intenção de ter um futuro estável $(4,1 \%-40$ citações); ter autonomia (3,9\% - 38 citações); por falta de opção $(2,5 \%$ 24 citações); e, para ter responsabilidade, com um percentual de $1,7 \%$, que representa 16 citações.

A Figura 6 a seguir indica as respostas apresentadas pelos alunos do $1^{\circ}$ ano (grupo 1$)$.

\section{FIGURA 6}

FATORES DETERMINANTES PARA A ESCOLHA DA PROFISSÃO SEGUNDO OS ALUNOS DO $1^{\circ}$ ANO

\begin{tabular}{|c|c|c|}
\hline & Qt. & $\%$ obs. \\
\hline Para fazer algo de útil à sociedade & 64 & $20,6 \%$ \\
\hline Para formaroutras pessoas & 55 & $17,7 \%$ \\
\hline Para a prender constantemente & 55 & $17,7 \%$ \\
\hline Pe lo prazer de explic ar e se fazer entender & 54 & $17,4 \%$ \\
\hline Sempre sonhei com is so & 51 & $16,5 \%$ \\
\hline Pelas oportunidades do mercado de trabalho & 51 & $16,5 \%$ \\
\hline Por opção & 46 & $14,8 \%$ \\
\hline Para u tilizar m in has capacidades & 28 & $9,0 \%$ \\
\hline Para ter um futuro es tável & 16 & $5,2 \%$ \\
\hline Para ter a u to nomia & 10 & $3,2 \%$ \\
\hline Por falta de opção & 7 & $2,3 \%$ \\
\hline Para ter responsabilidade & 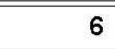 & $1,9 \%$ \\
\hline Tot al & 310 & \\
\hline
\end{tabular}

Um diferencial expressivo desse grupo é que o item referente à escolha da profissão por opção caiu da terceira (na amostra total) para a sétima colocação, com percentual de 14,8\% ( $\mathrm{N}_{1}=46$ citações). Anteriores 
a ela encontram-se os seguintes itens: o prazer de explicar e se fazer entender (ensinar), com 17,4\% das inferências $\left(\mathrm{N}_{1}=54\right.$ citações); e o sonho de ser professor, em conjunto com as oportunidades oferecidas pelo mercado de trabalho, com o mesmo percentual, 16,5\% ( $\mathrm{N}_{1}=51$ citações). Quanto ao grupo que tem a profissão docente por opção a porcentagem foi de $14,8 \%$ dos sujeitos $\left(\mathrm{N}_{1}=46\right.$ citações).

Por último, como questões de menor escolha, observam-se os seguintes itens: a utilização de suas capacidades ( $9 \%-\mathrm{N}_{1}=28$ citações); intenção de ter um futuro estável (5,2\% - $\mathrm{N}_{1}=16$ citações); ter autonomia $\left(3,2 \%-\mathrm{N}_{1}=10\right.$ citações); por falta de opção (2,3\% $-\mathrm{N}_{1}=7$ citações); e para ter responsabilidade, com percentual de 1,9\% ( $\mathrm{N}_{1}=6$ citações).

$\mathrm{Na}$ Figura 7, que demonstra a escolha de fatores determinantes dos alunos do $2^{\circ}$ ano, observa-se que os três primeiros itens, ainda que estejam em ordem de prioridade levemente invertida, apontam os mesmos aspectos levantados na amostra total $(\mathrm{N}=964)$. Como primeira opção aparece a expectativa de aprender constantemente $\left(20,7 \%-\mathrm{N}_{2}=\right.$ 106 citações); em segundo, a escolha por opção (intencionalidade) e também os que pretendem fazer algo útil à sociedade (ambos com $\mathrm{N}_{2}=93$ citações - 18,2\%). Os sujeitos que escolheram formar outras pessoas representam $16,6 \%$ da amostra, com $\mathrm{N}_{2}=85$ citações.

\section{FIGURA 7}

FATORES DETERMINANTES PARA A ESCOLHA DA PROFISSÃO SEGUNDO OS ALUNOS DO $2^{\circ}$ ANO

\begin{tabular}{|c|c|c|}
\hline & Qt. & $\%$ obs. \\
\hline Para aprender constantem en te & 106 & $20,7 \%$ \\
\hline Por opção & 93 & $18,2 \%$ \\
\hline Para fazer algo de útil à sociedade & 93 & $18,2 \%$ \\
\hline Para formaroutras pessoas & 85 & $16,6 \%$ \\
\hline Sempre sonhei com is so & 77 & $15,1 \%$ \\
\hline Pelo prazer de explic ar e se fazer entender & 74 & $14,5 \%$ \\
\hline Pelas oportunidades do mercado de trabalho & 70 & $13,7 \%$ \\
\hline Pa ra u tilizar m in has capacidades & 56 & $11,0 \%$ \\
\hline Para ter a u to nomia & 25 & $4,9 \%$ \\
\hline Para ter um futuro es tável & 22 & $4,3 \%$ \\
\hline Porfalta de opção & 14 & $2,7 \%$ \\
\hline Para ter responsabilid ade & 8 & $1,6 \%$ \\
\hline Tot al & 511 & \\
\hline
\end{tabular}


$\mathrm{Na}$ sequência dos itens mais citados, os sujeitos apontam o sonho de ser professor $\left(15,1 \%-\mathrm{N}_{2}=77\right.$ citações $)$; o prazer de explicar e se fazer entender (ensinar), com 14,5\% $\left(\mathrm{N}_{2}=74\right.$ citações); pelas oportunidades oferecidas pelo mercado de trabalho, com percentual de 13,7\% $\left(\mathrm{N}_{2}=70\right.$ citações); e aqueles que se reportam à utilização de suas capacidades, com $\mathrm{N}_{2}=56$ citações (11\%).

Quanto aos demais itens, mesmo com percentuais menores, têm-se a autonomia ( $4,9 \%-\mathrm{N}_{2}=25$ citações); a intenção de ter um futuro estável (4,3\% - $\mathrm{N}_{2}=22$ citações); a falta de opção $\left(2,7 \%-\mathrm{N}_{2}=14\right.$ citações); e, por último, a responsabilidade, com percentual de $1,6 \%\left(\mathrm{~N}_{2}=8\right.$ citações).

\section{FIGURA 8}

FATORES DETERMINANTES PARA A ESCOLHA DA PROFISSÃO SEGUNDO OS ALUNOS DO $3^{\circ}$ ANO

\begin{tabular}{|c|c|c|}
\hline & Qt. & $\%$ obs. \\
\hline Para a prender constantemente & 41 & $28,7 \%$ \\
\hline Por opção & 34 & $23,8 \%$ \\
\hline Para formaroutras pessoas & 32 & $22,4 \%$ \\
\hline Para fazer algo de út il à sociedade & 26 & $18,2 \%$ \\
\hline Sempre sonheicom is so & 23 & $16,1 \%$ \\
\hline Para u tilizar m in has capacidades & 19 & $13,3 \%$ \\
\hline Pelo prazer de explic ar e se fazer entender & 16 & $11,2 \%$ \\
\hline Pelas oportunidades do mercado de trabalho & 15 & $10,5 \%$ \\
\hline Para ter a u to nomia & 3 & $2,1 \%$ \\
\hline Porfalta de opção & 3 & $2,1 \%$ \\
\hline Para ter um futuro es tável & 2 & $1,4 \%$ \\
\hline Para ter responsabilidade & 2 & $1,4 \%$ \\
\hline Tot al & 143 & \\
\hline
\end{tabular}

Finalmente, para o grupo dos alunos do $3^{\circ}$ ano, mostrado na Figura 8, observa-se que as opções mais expressivas também coincidem com as escolhas da amostra total $(\mathrm{N}=964)$ e do grupo 2 (Figura 7). Novamente, encontram-se listadas as expectativas de aprender constantemente, com $\mathrm{N}_{3}=41$ citações $(28,7 \%$ - o maior percentual estabelecido para a questão); aqueles que escolheram a profissão por opção $(23,8 \%$; $\mathrm{N}_{3}=34$ citações); para formar outras pessoas, com percentual de $22,4 \%-$ $\mathrm{N}_{3}=32$ citações; e os que acreditam que a docência está ligada ao fazer algo útil à sociedade $\left(18,2 \%-\mathrm{N}_{3}=26\right.$ citações $)$. 
$\mathrm{Na}$ sequência, observam-se os seguintes itens: o sonho de ser professor $\left(\mathrm{N}_{3}=23\right.$ citações $\left.-16,1 \%\right)$; a utilização de suas capacidades $\left(13,3 \%-\mathrm{N}_{3}=19\right.$ citações); o prazer em explicar e se fazer entender $\left(11,2 \%-\mathrm{N}_{3}=16\right.$ citações); e os que optaram considerando as oportunidades oferecidas pelo mercado de trabalho, com 10,5\% ( $\mathrm{N}_{3}=15$ citações).

Quanto às opções menos escolhidas, têm-se: a expectativa de ter autonomia e, ainda, a falta de opção, ambas com percentual de $2,1 \%\left(\mathrm{~N}_{3}=\right.$ 3 citações cada), e a intenção de ter um futuro estável e ter responsabilidade, que também tiveram percentuais iguais, de 1,4\% ( $\mathrm{N}_{3}=2$ citações).

Observa-se, nessa categoria, que os fatores mais destacados pelos grupos, como determinantes na escolha da profissão, foram a aprendizagem constante, a "missão" de fazer algo útil à sociedade e formar outras pessoas (Figuras 5 a 8), compõem um cenário claramente articulado. Para desvelar os possíveis significados desse quadro, em primeira instância cabe retomar os argumentos da categoria anterior (motivação para a escolha da profissão) e referenciar o novo contrato de carreira para o século XXI. Segundo Hall (apud FROZINO, 2006), esse novo contrato está apoiado em vários fatores, entre eles o sucesso psicológico e a aprendizagem contínua.

Se essas prerrogativas determinam o perfil e as exigências sobre os profissionais de maneira geral, no caso dos professores, as Diretrizes Curriculares Nacionais para a Formação Docente (BRASIL, 2001) apontam que o ritmo acelerado das transformações científicas e tecnológicas altera também as necessidades de formação. Isso porque recai sobre a escola, entre outras, a responsabilidade de preparação das gerações atuais e futuras para o mercado de trabalho.

As diretrizes indicam que os docentes "[...] em seu próprio processo de aprendizagem [ou seja, na formação - possam desenvolver as] competências necessárias para atuar nesse novo cenário, reconhecendo-a [a formação] como parte de uma trajetória de formação permanente ao longo da vida" (BRASIL, 2001, p. 11). Assim, a aprendizagem torna-se uma exigência profissional, uma premissa fundamental, para exercício da docência.

No entanto, outros aspectos podem ser considerados relevantes, em relação aos resultados, entre eles a relação entre as respostas obtidas nesta categoria. Nessa perspectiva, deve-se considerar que os dados da pesquisa apontam as exigências da sociedade contemporânea como fato- 
res preponderantes na escolha profissional, o que indica que os sujeitos são mobilizados a responder, assimilando como próprias as atuais exigências sociais.

É interessante destacar que essa unanimidade (fatores mais relevantes) é apontada no que se refere ao extremo oposto, ou seja, os fatores menos considerados: a expectativa de ter autonomia, a intenção de ter um futuro estável e/ou responsabilidade. Nesse caso, é possível associar tais inferências ao processo histórico da profissão e da própria educação que, desde o início dos processos formais de ensino, vivenciou processos de controle, primeiro da Igreja, e depois do Estado, sobre as funções e ações dos centros preparatórios e da escola (NÓVOA, 1995).

Assim, compreendem-se as origens de vários fatores apontados pelos sujeitos pesquisados.

Em primeiro lugar, sobre os posicionamentos que refletem a "utilidade da ação educativa à sociedade", pois, segundo Nóvoa (1995), a influência dos princípios religiosos (normas, valores, crenças e atitudes morais religiosas) perdura nos atores da educação. Conforme o autor, “[...] mesmo quando a missão de educar é substituída pela prática de um ofício e a vocação cede lugar à profissão, as motivações originais não desaparecem" (NÓVOA, 1995, p. 16).

Em segundo lugar, mais diretamente no que se refere aos aspectos de responsabilidade e/ou autonomia, assim como à questão da estabilidade (ou melhor, à falta delas), é importante destacar o perfil prescritivo e hierarquicamente imposto por instituições ou poderes externos ao universo escolar propriamente dito. Em outras palavras, ora a Igreja (a bem do controle social) ora o Estado (a bem da estratificação e da manutenção do status quo) geraram resultados como a "[...] desprofissionalização (ou proletarização) a que os professores têm estado sujeitos" (NÓVOA, 1995, p. 21). No final do século XX, com a promulgação da LDBEN n.. 9.394/96, os Sistemas de Ensino, as escolas e, consequentemente, seus atores são oficialmente desafiados ao exercício da autonomia, o que, no momento, soa como mais uma batalha e fase de grande instabilidade aos profissionais.

Nesse sentido, destaca-se que as mudanças dos modelos educacionais já atribuíram à função docente vários perfis de atuação. Primeiramente, um perfil no qual o professor era o "dono do conhecimento e da verdade"; em seguida, de transmissor de conhecimentos aos 
papéis de técnico, mediador, investigador e, atualmente, ou melhor, em fase de transição, o professor reflexivo. Este último demanda não só o exercício pleno da autonomia nas ações didático-metodológicas, mas também condições que lhe permitam a reflexão como ação contínua e provedora de sua própria profissionalização e aprendizagem permanente.

Para Azanha (apud MELLO, 2004, p. 35), "O projeto pedagógico da escola é apenas uma oportunidade para que algumas coisas aconteçam e dentre elas o seguinte: [...] definição das responsabilidades coletivas e pessoais para eliminar ou atenuar falhas detectadas". Tal afirmativa tem sentido ainda maior, visto que a asserção profissional dos professores "[...] é um percurso repleto de lutas e conflitos, de hesitações e de recuos. $\mathrm{O}$ campo educativo está ocupado por inúmeros actores (Estado, Igreja, famílias) que sentem a consolidação do corpo docente como uma ameaça aos seus interesses e projectos" (NÓVOA, 1995, p. 21).

Essa situação pode relacionar-se ao que o autor apresenta como uma das consequências do mal-estar docente gerado no seio da crise. Nesse caso, o recurso sistemático a "[...] discursos-alibi de desculpabilização e ausência de uma reflexão crítica sobre a acção profissional" (NÓVOA, 1995, p. 22), imagem esta que acarretaria inversões de valores, ou melhor, equívocos na compreensão do que a realidade escolar efetivamente demanda aos profissionais da área.

Por fim, cabe retratar que os dados obtidos refletem, de certa forma, a imagem transposta socialmente e aquela construída pelos indivíduos e que caracterizam a visão e as expectativas dos sujeitos sobre a própria profissão docente.

\section{Concepções sobre a profissão}

As figuras a seguir indicam as concepções e expectativas dos sujeitos, no total e por grupo, com relação à profissão docente, destacando os vários determinantes dessas concepções e sua ligação com a motivação para a escolha da profissão e a identidade profissional. 
FIGURA 9

CONCEPÇÕES E EXPECTATIVAS SOBRE A PROFISSÃO - AMOSTRA TOTAL DE SUJEITOS

\begin{tabular}{|l|r||r|}
\hline & \multicolumn{1}{|c|}{ Média } & Frequên cia \\
\hline É Útil & 4,66 & 964 \\
\hline \hline Requer criativ idade & 4,66 & 964 \\
\hline \hline É Desaf iadora & 4,48 & 964 \\
\hline \hline É Bonita & 4,35 & 964 \\
\hline \hline É dinâmica & 4,29 & 964 \\
\hline \hline É atraente & 3,88 & 964 \\
\hline \hline É complexa & 3,85 & 964 \\
\hline \hline É Pesada & 3,52 & 964 \\
\hline \hline É Valoriz ada & 2,42 & 964 \\
\hline \hline Total & 4,01 & \\
\hline
\end{tabular}

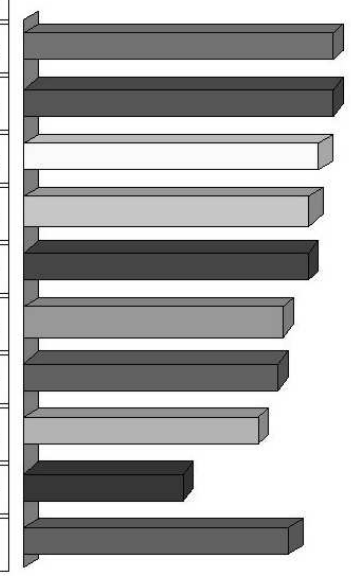

FIGURA 10

CONCEPC̣ÕES E EXPECTATIVAS SOBRE A PROFISSÃO - AMOSTRA DOS ALUNOS DO $1^{\circ}$ ANO

\begin{tabular}{|l|r||r|}
\hline & \multicolumn{1}{|c|}{ Méd ia } & Frequência \\
\hline É Útil & 4,61 & 310 \\
\hline \hline Requer criativ idade & 4,59 & 310 \\
\hline \hline É Des af iadora & 4,39 & 310 \\
\hline \hline É Bonita & 4,30 & 310 \\
\hline \hline É dinâmica & 4,26 & 310 \\
\hline \hline É atraente & 3,77 & 310 \\
\hline \hline É complexa & 3,77 & 310 \\
\hline \hline É Pesada & 3,48 & 310 \\
\hline \hline É Valoriz ada & 2,63 & 310 \\
\hline \hline Total & 3,98 & \\
\hline
\end{tabular}

Conforme indicado na Figura 9, o total de sujeitos da amostra $(\mathrm{N}=964)$ considera que a profissão docente é útil para a sociedade e que requer criatividade, questões que atingiram média de $\mathrm{M}_{\mathrm{t}}=4.66$. Em segui$\mathrm{da}$, os sujeitos apontaram o fato de a profissão ser desafiadora $\left(\mathrm{M}_{\mathrm{t}}=4.48\right)$, bonita $\left(M_{t}=4.35\right)$ e dinâmica $\left(M_{t}=4.29\right)$.

Com médias um pouco menores, os sujeitos afirmam que a profissão é atraente $\left(\mathrm{M}={ }_{\mathrm{t}} 3.88\right)$, complexa $\left(\mathrm{M}_{\mathrm{t}}=3.85\right)$ e pesada $\left(\mathrm{M}_{\mathrm{t}}=3.52\right)$. Por último, consideram que é valorizada, item que atingiu média de $\mathrm{M}_{\mathrm{t}}=2.42$. 
Nos resultados obtidos junto ao grupo $1\left(\mathrm{~N}_{1}=310\right)$, apresentados na Figura 10, observa-se que os alunos do $1^{\circ}$ ano conferem médias similares às apontadas pela amostra total de sujeitos, pois, na mesma sequência, a concepção dos alunos é de que se trata de uma profissão útil para a sociedade $\left(\mathrm{M}_{1}=4.61\right)$; que requer criatividade, com média de $\mathrm{M}_{1}=$ 4.59; é desafiadora $\left(\mathrm{M}_{1}=4.39\right)$, bonita $\left(\mathrm{M}_{1}=4.30\right)$ e dinâmica $\left(\mathrm{M}_{1}=4.26\right)$.

Com médias iguais, os sujeitos avaliam-na como uma profissão atraente e complexa $\left(\mathrm{M}_{1}=3.77\right)$. A ideia de ser pesada atingiu média de $\mathrm{M}_{1}=3.48$ e, por último, valorizada $\left(\mathrm{M}_{1}=2.63\right)$.

FIGURA 11

CONCEPC̣ÕES E EXPECTATIVAS SOBRE A PROFISSÃO - AMOSTRA DOS ALUNOS DO $2^{\circ}$ ANO

\begin{tabular}{|l|r||r|}
\hline & \multicolumn{1}{|c|}{ Méd ia } & Frequên cia \\
\hline Requer criativ idade & 4,70 & 511 \\
\hline \hline É Útil & 4,68 & 511 \\
\hline \hline É Des af iadora & 4,51 & 511 \\
\hline \hline É Bon ita & 4,40 & 511 \\
\hline \hline É dinâmica & 4,31 & 511 \\
\hline \hline É atraente & 3,95 & 511 \\
\hline \hline É complexa & 3,90 & 511 \\
\hline \hline É Pesada & 3,56 & 511 \\
\hline \hline É Valoriz ada & 2,35 & 511 \\
\hline \hline Total & 4,04 & \\
\hline
\end{tabular}

FIGURA 12

CONCEPC̣ÕES E EXPECTATIVAS SOBRE A PROFISSÃO - AMOSTRA DOS ALUNOS DO $3^{\circ}$ ANO

\begin{tabular}{|l|r||r|}
\hline & \multicolumn{1}{|c||}{ Média } & Frequência \\
\hline É Útil & 4,72 & 143 \\
\hline \hline Requer criativ ida de & 4,62 & 143 \\
\hline \hline É Desaf iadora & 4,54 & 143 \\
\hline \hline É Bonita & 4,29 & 143 \\
\hline \hline É din âmica & 4,26 & 143 \\
\hline \hline É atraente & 3,87 & 143 \\
\hline \hline É complexa & 3,84 & 143 \\
\hline \hline É Pesada & 3,47 & 143 \\
\hline \hline É Valoríada & 2,19 & 143 \\
\hline \hline Total & 3,98 & \\
\hline
\end{tabular}

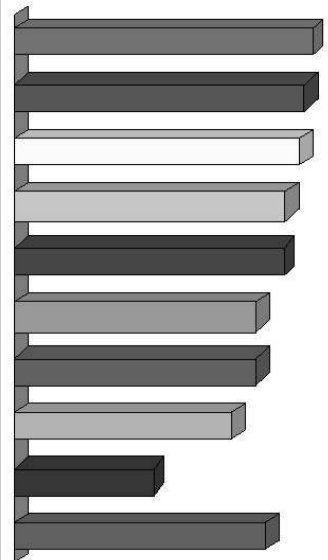


Em relação aos resultados do grupo $2\left(\mathrm{~N}_{2}=511\right)$, como mostrado na Figura 11, com exceção de uma pequena inversão entre a questão da criatividade $\left(\mathrm{M}_{2}=4.70\right)$ e a concepção de utilidade para a sociedade $\left(\mathrm{M}_{2}=4.68\right)$, os posicionamentos permanecem iguais aos da amostra total (Figura 9) e aos obtidos junto aos alunos do $1^{\circ}$ ano (Figura 10), ou seja, os sujeitos acreditam que a profissão é desafiadora $\left(\mathrm{M}_{2}=4.51\right)$, bonita $\left(\mathrm{M}_{2}=4.40\right)$ e dinâmica $(\mathrm{M}=4.31)$.

Quanto às demais características, encontramos a ideia de uma profissão atraente $\left(\mathrm{M}_{2}=3.95\right)$, complexa $\left(\mathrm{M}_{2}=3.90\right)$ e pesada $(\mathrm{M}=3.56)$. Já a valorização atingiu média de $\mathrm{M}_{2}=2.35$.

Em relação aos resultados para os alunos do $3^{\circ}$ ano $\left(\mathrm{N}_{3}=143\right)$, mostrados na Figura 12, os dados obtidos corroboram os posicionamentos dos grupos anteriores. Tem-se, novamente, o fato de a profissão ser vista como útil para a sociedade $\left(\mathrm{M}_{3}=4.72\right)$, requerer criatividade $\left(\mathrm{M}_{3}=\right.$ 4.62) e ser desafiadora $\left(\mathrm{M}_{3}=4.54\right)$.

Segundo os sujeitos do grupo 3, a profissão docente também é bonita e dinâmica, aspectos que obtiveram médias de $\mathrm{M}_{3}=4.29$ e $\mathrm{M}_{3}=$ 4.26 , respectivamente. E, com médias um pouco menos expressivas, os sujeitos apontaram a profissão como atraente $\left(\mathrm{M}_{3}=3.87\right)$, complexa $\left(\mathrm{M}_{3}=\right.$ 3.84) e pesada $\left(\mathrm{M}_{3}=3.47\right)$. Por último, tem-se a valorização, item que atingiu média de $\mathrm{M}_{3}=2.19$.

Pode-se observar, portanto, que as concepções sobre a profissão apresentam-se exatamente as mesmas para todos os grupos, à exceção de uma inversão entre criatividade e utilidade para os alunos do $2^{\circ}$ ano. Entretanto, como a diferença entre esses itens é mínima, vê-se que, essencialmente, todos os sujeitos, independentemente do ano de estudo, têm um posicionamento idêntico.

Assim, é possível inferir que as respostas dadas pelos sujeitos sugerem a influência de representações na construção das concepções que compõem o ideário dos professorandos e influenciam na construção do Ideal Profissional. No entanto, é importante buscar as possíveis raízes desse conjunto incorporado e mantido pelos sujeitos, pois são elementos que, direta e indiretamente, constroem sua identidade profissional e, consequentemente, o perfil de suas práticas em sala de aula.

Diante dessas questões, verificam-se indícios sobre a origem de vários aspectos apontados nos resultados, como o ideário de que a profissão está a serviço da sociedade, ou melhor, de sua "utilidade". Aqui, vale 
destacar que a educação e seus atores fazem parte da teia complexa das redes sociais. Segundo Sacristán (1995, p. 66), “[...] o ensino é uma prática social, não só porque se concretiza na interação entre professores e alunos, mas também porque estes atores refletem a cultura e contextos sociais a que pertencem". Neste sentido, há que se considerar que os fatores que configuram a ação docente como coletivo social sofrem influência da sociedade, de contextos complexos, que variam, inclusive, em função dos níveis de escolaridade nos quais os professores atuam.

Vale ressaltar, também, que, sob novas e atualizadas formas, as exigências sobre as escolas e os profissionais da educação permanecem grandiosas. Tanto que Libâneo (apud Unesco, 2004) chama a atenção para o fato de que se espera, atualmente, que as instituições de ensino respondam à responsabilidade de formar cidadãos competentes na compreensão crítica das transformações, em escala planetária. Cidadãos que sejam preparados, na escola, para pensar cientificamente e colaborar em processos de construção de uma "nova postura ético-valorativa". Libâneo (apud UNESCO, 2004, p. 28) ressalta que "[...] a escola tem um grande papel no fortalecimento da sociedade civil, das entidades, das organizações e movimentos sociais. Ora, tudo o que esperamos da escola para os alunos são, também, exigências colocadas aos professores". Nesse sentido, os discursos gerados por meio dos documentos oficiais e também no seio da sociedade são agentes de construção e manutenção das representações existentes sobre a profissão.

Sobre outros aspectos que atingiram médias significativas, como a necessidade de criatividade $\left(\mathrm{M}_{\mathrm{t}}=4.66\right)$ e o conceito de desafiadora $\left(\mathrm{M}_{\mathrm{t}}=4.48\right)$, cabe destacar que se encontram imbricados naturalmente. Essa compreensão parte do pressuposto (CLARK; YINGER apud WOODS, 1995) de que a complexidade, a incerteza, os conflitos e as especificidades que envolvem o trabalho docente tornam únicas as situações de ensino enfrentadas no cotidiano escolar. Exige-se dos professores, portanto, o uso constante da criatividade para a solução das situações vivenciadas. As inovações e a volatilidade, características da sociedade contemporânea, terminam por impor a necessidade de novas alternativas a todo instante.

É aparente que as próprias transformações sociais tornam o cenário educativo um espaço de complexidades e incertezas, questões que terminam afetando diretamente a identidade profissional docente, além de 
gerarem a insegurança dos professores sobre suas práticas, saberes e competências, tornando desafiadoras as perspectivas ligadas ao ofício.

Quanto a aspectos relacionados à ideia de a profissão ser atraente $\left(\mathrm{M}_{\mathrm{t}}=3.88\right)$, dinâmica $\left(\mathrm{M}_{\mathrm{t}}=4.29\right)$ ou mesmo bonita $\left(\mathrm{M}_{\mathrm{t}}=4.35\right)$, acredita-se que essas concepções estejam ligadas à idealização da profissão, principalmente quando o grupo pesquisado tem como marca (a maioria de seus componentes) a falta de experiência no magistério. Mesmo se consideradas as práticas de estágio vivenciadas nos cursos de formação, é importante reconhecer que são ações ainda limitadas em termos de experiência profissional, que não traduzem completa e extensivamente a realidade das necessidades, especificidades e dificuldades da profissão.

Nesse contexto, a experiência é uma questão profunda, pois, segundo Esteve (1995), estudos realizados em diversos países indicam que mesmo a formação inicial fomenta uma visão idealizada do ensino, pois não trata de forma real as situações a serem enfrentadas no cotidiano escolar.

Nesse sentido, Veenman (apud ESTEVE, 1995) faz uso de um conceito chamado de "choque com a realidade" para expor a quebra da "imagem ideal" diante das dificuldades e complexidades reais existentes no trabalho docente. $\mathrm{O}$ autor, inclusive, aborda a atitude dos professores diante dessa ruptura, fazendo uma alusão às posturas docentes frente às mudanças dos sistemas de ensino, já que a mudança de paradigmas proposta faz ruir os alicerces basilares tradicionais.

Esse cenário confirma uma nova crise de identidade docente, definida como uma "[...] contradição entre o eu real (o que eles são diariamente nas escolas) e o eu ideal (o que eles queriam ser ou pensam que deveriam ser)" (ABRAHAM apud ESTEVE, 1995, p. 110). Tal posicionamento ratifica a abordagem de Borba (2001, p. 40), que observa: "O reconhecimento da identidade profissional é mais amplo que o próprio trabalho, pois está intimamente associado a outros espaços de legitimação de saberes e de competências nos sistemas de ação". E é nessa relação que se estabelece a "dinâmica transacional" entre a identidade dos sujeitos diante das instituições e a identidade própria, relacionada às suas histórias de vida.

Nesse particular, portanto, deve-se considerar que as concepções sobre a profissão são construções compostas de experiências pessoais e profissionais, valores, crenças e conhecimentos empíricos, ou seja, 
ideários sociais construídos ao longo de toda a trajetória de cada indivíduo e diante das quais o curso de formação não consegue deflagrar novas reflexões ou, ainda, não está intencionalmente estruturado para confrontá-las.

Por último, nos dados relacionados à valorização da profissão, verificou-se a média de $\mathrm{M}_{\mathrm{t}}=2.42$. Nesse aspecto, vale destacar que tais posicionamentos corroboram outros resultados já obtidos, como a pesquisa da Unesco (2004), que revela questões como a baixa remuneração. Observa-se que as condições do grupo pesquisado, com relação à renda pessoal e familiar, apontam para sujeitos pertencentes a classes sociais desfavorecidas. Entretanto, não é somente a questão econômica que denota a desvalorização da profissão. Outros aspectos importantes intervêm na valorização profissional dos docentes, além dos econômicos.

Segundo Esteve (1995), a perda do apoio social ao sistema educativo, ou seja, o descrédito - fruto das expectativas frustradas de que a educação venha a favorecer um futuro melhor -, atinge o contexto social do ensino de maneira geral. No entanto, tende a recair sobre os professores a culpa pelos resultados negativos da aprendizagem dos alunos, não sendo considerados fatores sistêmicos amplos (da própria escola e fora dela).

Outro aspecto considerável é a falta de incentivo institucional aos projetos pessoais de educação continuada. Observou-se, nos sujeitos deste estudo, que apenas $0,4 \%$ da amostra total recebe algum tipo de apoio financeiro para a formação. Esse dado, em conjunto com a baixa renda pessoal, sinaliza as dificuldades enfrentadas para o engajamento em projetos de desenvolvimento profissional, o que termina por limitar, também, as possibilidades de ascensão. Diante desse quadro, deduz-se que essa realidade é assimilada como uma espécie de falta de reconhecimento do sistema de ensino com relação ao trabalho docente realizado.

\section{Considerações finais}

É importante retomar a questão central do trabalho, visto que o conjunto dos fatores que influenciam na escolha dos sujeitos pela carreira do magistério, assim como suas concepções sobre a profissão, compõe um conjunto importante de significados para a construção da carreira docente. 
Vale destacar que os resultados remetem, de forma direta, a elementos próprios à identidade profissional docente do grupo estudado, elementos que correspondem muito mais a um Ideal Profissional docente, construído historicamente a partir das concepções correntes na sociedade, do que a um Eu Profissional, cuja concretização ainda aguarda experiência profissional mais consolidada.

De fato, no conjunto dos fatores motivadores à escolha da carreira e, ainda, nas concepções dos sujeitos sobre a profissão, é observada forte influência das reminiscências históricas que, de certa forma, contribuem para o reforço de ideários sociais existentes. Nos dados obtidos, isso pode ser visualizado na:

- responsabilização do professor pelo sucesso e pela qualidade do ensino (Figura 1), que aponta para as influências histórico-sociais de origem da profissão docente e para os referenciais ainda mantidos socialmente, sobre a responsabilidade heroica e sacerdotal do professor frente ao processo educativo. Considere-se, também, o crescimento contínuo e ainda incerto das reais atribuições e papéis a serem desempenhados por esses profissionais diante da escola e da sociedade atual;

- baixa representatividade de elementos, como o tipo de trabalho (Figura 1). Segundo Hall (apud FROZINO, 2006), a definição da carreira está intrinsecamente ligada às atitudes e aos comportamentos que os indivíduos vivenciam ao longo do tempo, no desempenho de suas atividades. Dessa forma, as crenças, ideias, opiniões e os conhecimentos do professor têm influências sobre suas decisões em sala de aula (MIZUKAMI; LOURENCETTI, 2004).

Outro aspecto latente são as consequências da visão de (des)valorização (Figura 9) que cerca o exercício do magistério. Nesse particular, aparentemente, a falta de valorização da profissão não afeta a motivação ou a determinação dos sujeitos em seguirem a carreira docente. No entanto, não podem ser desconsiderados os reflexos e a influência desse fator na imagem dos profissionais da área.

$\mathrm{Na}$ verdade, os resultados dessa categoria indicam que a imagem projetada pelos sujeitos sobre a profissão encontra-se em conflito, tal qual sua identidade profissional. Esteve (1995) aponta que a realidade selecionada e homogeneizada de outrora se contrapõe àquela voltada para a escolarização das massas. Isso significa, na prática, o enquadramento de "[...] cem por cento as crianças de um país, com os cem por cento de problemas sociais que [...] levam consigo. Daí o desencanto que atinge mui- 
tos professores, que não souberam redefinir o seu papel perante esta nova situação" (ESTEVE, 1995, p. 96).

Tais dados denotam, também, a confirmação de conflitos vivenciados no processo transitório entre o paradigma tradicional, que não responde mais às atuais demandas educacionais e sociais, e um paradigma emergente, que ainda não está claramente configurado (GADOTTI, 2000).

Segundo Gadotti (2000), os desafios postos diretamente aos sistemas escolares, como o dilema dos avanços no atendimento quantitativo de alunos, agora devem ser superados, para que se possa garantir qualidade ao ensino ofertado. Neste particular, aponta-se, entre os fatores determinantes na escolha da carreira, a importância da aprendizagem constante $\left(\mathrm{N}_{\mathrm{t}}=21 \%\right.$ - Figura 5), pois, segundo Esteve (1995, p. 98), o avanço rápido e permanente das ciências e a necessidade de integração de novos saberes e conteúdos ao processo de ensino gera a "[...] necessidade de renovação permanente em que os professores têm que aceitar mudanças profundas nas concepções e no desempenho de sua profissão [...] pois um ensino de qualidade torna-se cada vez mais imprescindível". Diante dessa questão, é possível inferir que as respostas dadas pelos sujeitos estão ligadas a representações e idealizações existentes e à necessidade de sentiremse prontos a responder às exigências do contexto social e do mercado de trabalho. 


\section{REFERÊNCIAS}

BORBA, A. M. Identidade em construção: investigando professores na prática da avaliação escolar. São Paulo: EDUC; Santa Catarina: Univali, 2001.

BRASIL. Ministério de Educação e do Desporto. Conselho Nacional de Educação. Diretrizes curriculares nacionais para a formação de professores da educação básica. Brasília, DF: MEC; CNE, 2001.

BUENO, B. O. Pesquisa em colaboração na formação contínua de professores. In: BUENO, B. O.; CATANI, D. B.; SOUSA, C. P. A vida e o oficio dos professores. Formação contínua, autobiografia e pesquisa em colaboração. 2. ed. São Paulo: Escrituras, 2000. p. 7-20.

CHAMON, E. M. Q. O. Formação e (Re) construção identitária: estudo das memórias de professores do ensino básico inscrito em um programa de formação continuada. 2003. 117 f. Tese (Pós-Doutorado em Educação) - Faculdade de Educação, Universidade Estadual de Campinas, Campinas, 2003.

CUNHA, M I. Docência na universidade, cultura e avaliação institucional: saberes silenciados em questão. Revista Brasileira de Educação, Rio de Janeiro, v. 11, n. 32, maio/ago. 2006.

ESTEVE, J. M. Mudanças sociais e função docente. In: NÓVOA. A. (Org.). Profissão professor. Portugal: Porto, 1995.

FROZINO, A. D. Formação Profissional: percursos e desafios para a escolha de carreira. 2006. 152 p. Dissertação (Mestrado) - Pós-graduação em Gestão e Desenvolvimento Regional, UNITAU, Taubaté, 2006.

GADOTTI, M. Perspectivas atuais da Educação. São Paulo, 2000.

GOHN, M. G. Educação não-formal e cultura política. São Paulo: Cortez, 1999.

GRIGOROWITSCHS, T. O conceito de socialização caiu em desuso? Uma análise dos processos de socialização na infância com base em Georg Simmel e George H. Mead. Educação e Sociedade, Campinas, vol. 29, n. 102, p. 33-54, jan./abr. 2008.

MELLO, G. N. de. Educação escolar Brasileira: O que trouxemos do século XX? São Paulo: Artmed, 2004.

MIZUKAMI, M. G. N.; LOURENCETTI, G. C. Dilemas de professoras em práticas cotidianas. In: MIZUKAMI, M. G. N.; REALI, A. M. M (Orgs.). Aprendizagem profissional da docência: saberes, contextos e práticas. São Paulo: EdUFScar, 2004.

MIZUKAMI, M. G. N.; REALI, A. M. M. R. Práticas profissionais, formação inicial e diversidade: análise de uma proposta de ensino aprendizagem. In: MIZUKAMI, M. G. N.; REALI, A. M. M. R. (Org.). Aprendizagem profissional da docência: saberes, contextos e práticas. São Carlos: EdUFSCar, 2002.

NÓVOA, A. (org). O passado e o presente dos professores. In: NÓVOA. A. (Org.) Profissão Professor. Portugal: Porto, 1995.

NÓVOA, A. Relação Escola-Sociedade: “novas respostas para um velho problema”. In: SERBINO, R. V. et al. (Org.). Formação de professores. São Paulo: Unesp, 1998. p. 19-39. NÓVOA, A. Os professores e as histórias da sua vida. In: NÓVOA, A. (Org.). Vidas de professores. 2. ed. Porto: Porto Editora, 2000. p. 11-30.

NÓVOA, A. Cúmplices ou reféns? Revista Nova Escola, [S.1.], Maio, n. 162, p. 14, 2003. 
PIMENTA, S. G. Formação de Professores: identidade e saberes da docência. In: PIMENTA, S. G. (Org.). Saberes pedagógicos e atividade docente. 4. ed. São Paulo: Cortez, 2005.

SACRÍSTAN, J. G. Consciência e ação sobre a prática como libertação profissional dos professores. In: NÓVOA, A. (Org.). Profissão professor. Portugal: Porto, 1995.

UNESCO, O. N. U. E. C. C. O perfil dos professores brasileiros: o que fazem, o que pensam, o que almejam. São Paulo: Moderna, 2004.

WOODS, P. Aspectos sociais da criatividade do professor. In: NÓVOA, A. (Org.).

Profissão professor. Portugal: Porto, 1995. 


\section{NOTAS}

${ }^{1}$ Este artigo é resultado da discussão sobre "Formação de professores em Belém-Pará: um estudo transversal sobre as Diretrizes Curriculares Nacionais, saberes, práticas e a identidade profissional docente", pesquisa realizada para dissertação de mestrado no curso de Gestão e Desenvolvimento Regional, da Universidade de Taubaté - Unitau.

2 Esta pesquisa contou com o apoio do CNPq por meio do Projeto Universal 470338/2008-3 - Identidade e Formação Docentes.

Recebido: $14 / 05 / 2009$

Aprovado: 09/09/2011

Contato:

Avenida Almirante Barroso, 777

Marco

CEP 66093-020

Belém, Pará

Brasil 